\title{
Isolation of Catechins from Roscoea purpurea
}

\author{
Gunpreet Kaur ${ }^{1}$, Vikas Gupta ${ }^{1}$, RG Singhal ${ }^{2}$, RK Rawal ${ }^{3}$, Parveen Bansal ${ }^{1, *}$ \\ 'University Center of Excellence in Research, Baba Farid University of Health Sciences, Faridkot, Punjab, INDIA. \\ ${ }^{2} S c h o o l$ of Basic and Applied Sciences Shobhit University, Meerut, Uttar Pradesh, INDIA. \\ ${ }^{3}$ Department of Chemistry, Maharishi Markandeshwar University, Mullana, Haryana, INDIA.
}

\begin{abstract}
Background: Roscoea purpurea also known as Kakoli is an endangered species of "Ashtawarga" group which faces immense identification and authentication crisis in Ayurvedic literature. Due to less availability and high medicinal value of Kakoli plant, adulteration and substitution was done by drug manufacturers. Objectives: This scientific investigation was carried out to isolate discrete and specific chemical compounds from Kakoli using chromatographic and spectral analysis techniques for quality standardization and identification of Kakoli containing herbal formulations. Materials and Methods: The methanol root extract of plant was used for phytochemical screening and isolation of marker compounds. Two compounds with $R_{f}$ values 0.51 and 0.73 respectively were isolated and purified by using mobile phase ethyl acetate: $n$-hexane: formic acid (07: 03: $0.1 \mathrm{v} / \mathrm{v} / \mathrm{v})$. Characterization of isolated compounds was done with help of melting point and spectral analysis. Results: The blackish brown methanol extract showed the presence of flavonoids, alkaloids, terpenoids, phenolic phytosterols and amino acid. The final isolated compounds were of off white and yellowish white with melting point range of $217-220^{\circ} \mathrm{C}$ and 239 -
\end{abstract}

$242^{\circ} \mathrm{C}$ respectively and molecular ion peak at $\mathrm{m} / \mathrm{z} 329(\mathrm{M}+\mathrm{Na})$ and at 291 $(\mathrm{M}+\mathrm{H})$ being according to the proposed structure of Epigallocatechin and Epicatechin respectively. Conclusion: In present study Epigallocatechin and Epicatechin were isolated for the first time and may prove potential tools for differentiation and accurate identification of the authentic plant from its official substitutes and cheap common adulterants.

Key words: Chromatography, Epigallocatechin, Epicatechin, Kakoli, Roscoea purpurea, Standardization.

Correspondence

Dr. Parveen Bansal

Joint Director, University Centre of Excellence in Research, Baba Farid University of Health Sciences, Faridkot-151203, Punjab, INDIA.

Phone: +91-01639-256232

Email: ucer_bfuhs@rediffmail.com

DOI: 10.5530/jyp.2020.12.99

\section{INTRODUCTION}

Roscoea purpurea also known as Kakoli is an endangered species of "Ashtawarga" group which contains Jivaka-Rishibhak, Mahameda-Meda, Riddhi-Vriddhi and Kakoli-Kshirakakoli plants. ${ }^{1-4} R$. purpurea belonging to Zingiberaceae family is a large lush green plant with thick, fleshy leaves and two-tone purple hooded flowers. ${ }^{5}$ Tuberous roots of kakoli have been reported to contain active phenolic compounds, alkaloids, saponins, flavonoids, tannin etc. Many other scientific studies have reported immunomodulatory, spermatopiotic, antidiabetic and antitubercular activities too. ${ }^{6,7}$ But due to less availability and high medicinal value of Kakoli plant, adulteration and substitution with similar or low grade, inferior quality product was done by drug manufacturers due to which faith in herbal drugs decreases. ${ }^{7}$ Advanced modified quality control and analytical techniques have played a vital role in improvement of quality of poly-herbal formulations. World Health Organization also emphasizes use of advanced analytical techniques for ensuring the quality of formulations. ${ }^{5}$ Thus, for quality standardization, differentiation and identification of Kakoli containing herbal products and formulations there is a need for bringing out discrete and specific chemical compounds from Kakoli using chromatographic and spectral analysis techniques. Hence, this scientific investigation was carried out to isolate chemical marker compound from Kakoli with help of chromatographic and spectral analysis techniques.

\section{MATERIALS AND METHODS}

\section{Chemicals and Plant material}

The plant $R$. purpurea was obtained from a cultivated source from Himachal Pradesh and got authenticated vide letter NBRI/CIF/524/2016 from National Botanical Research Institute, Lucknow. Root samples of the plant were cleaned with water, dried in shade and stored for further use in air tight containers. Only analytical grade chemicals, reagents and organic/inorganic solvents were used in the study.

\section{Preparation of extract}

After defatting with petroleum ether, the coarsely powdered root samples were subjected to continuous hot extraction process with methanol. The filtered extract thus obtained was then evaporated to form a semisolid mass which was then stored in desiccator for further use.

\section{Phytochemical screening}

Phytochemical screening was performed to detect alkaloids, saponins, tannins, steroids, flavonoids, terpenoids, glycosides, proteins, phenolics, carbohydrates and amino acids. ${ }^{8,9}$

\section{Isolation of chemical marker}

After phytochemical screening, column chromatography of extract was done for isolation of active marker compound About $8.4 \mathrm{~g}$ of methanol extract was mixed with methanol and adequate silica gel (pore size 60$120 \mathrm{mesh}$ ) to form free flowing slurry. About $675 \mathrm{~g}$ silica gel suspension prepared in $n$-hexane was charged into the glass column having dimension $1000 \mathrm{~mm} \times 50 \mathrm{~mm}$ and allowed to stand overnight to form a uniform silica bed. After 12-14 hrs, column was eluted with solvents like $n$-hexane followed by increase in polarity of solvent by addition of toluene, isopropyl alcohol, $\mathrm{CHCl}_{3}$, ethyl acetate in different ratio. A fraction of $100 \mathrm{ml}$ was collected at an optimized flow rate of $10 \mathrm{ml} / \mathrm{min}$.

This is an open access article distributed under the terms of the Creative Commons Attribution-NonCommercial-ShareAlike 4.0 License, which allows others to remix, tweak, and build upon the work non-commercially, as long as the author is credited and the new creations are licensed under the identical terms. 
TLC of collected fractions was performed with hit and trial method by using different solvents. Elution with solvent system chloroform: ethyl acetate 30:70 resulted in a pool of three compounds with $\mathrm{R}_{f} 0.20,0.51$, 0.73 on TLC plates by using ethyl acetate: $n$-hexane: formic acid (07: 03 : $0.1 \mathrm{v} / \mathrm{v} / \mathrm{v}$ ) as mobile phase. Two compounds having $\mathrm{R}_{f}$ values 0.51 and 0.73 were isolated and purified respectively with methanol., ${ }^{9,10}$

\section{Characterization of isolated chemical compound}

Melting point and spectral analysis (IR, NMR and Mass spectroscopy) techniques were used for chemical characterization of newly isolated compounds.

\section{RESULTS}

Isolated compounds were characterized by melting point test, spectral analysis and compared with literature. For identification of structure of isolated compounds different spectroscopic techniques (IR, NMR and Mass) were used.

\section{Phytochemical screening of the extract}

On phytochemical screening, the blackish brown methanol extract showed the presence of alkaloids, phytosterols, flavonoids, terpenoids, phenolics, proteins and amino acid.

\section{Characterization and identification of isolated compounds}

Physicochemical description: Color of isolated compound 1 and compound 2 were found to be off white and yellowish white respectively after crystallization from methanol.

Chemical test: The isolated compounds were shown positive test of flavonoids.

Melting point: The melting point range of compound 1 and compound 2 were found to be $217-220^{\circ} \mathrm{C}$ and $239-242^{\circ} \mathrm{C}$ respectively.

\section{Spectral Analysis of Isolated Compounds}

\section{IR spectrum}

IR spectra of compound $1\left(\mathrm{KBr}, v, \mathrm{~cm}^{-1}\right): 3300.76(\mathrm{O}-\mathrm{H}), 2943.13-$ $2831.32(\mathrm{C}-\mathrm{H}), 1450.79-1414.65$ (C-O-C), 1022.67 (C-O) confirm the skeleton of epigallocatechin.

IR spectra of compound $2\left(\mathrm{KBr}, v, \mathrm{~cm}^{-1}\right)$ : 3293(O-H), 2910(C-H), $1607(\mathrm{C}=\mathrm{C})$ confirms the skeleton of epicatechin.

\section{NMR spectrum}

${ }^{1} \mathrm{H}$ NMR spectra of compound $1\left(300 \mathrm{MHz} ; \mathrm{CDCl}_{3}\right)$ : d 1.25-2.30 (6xOAc,

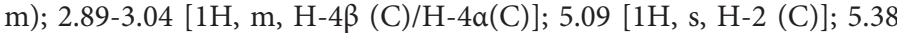
$[1 \mathrm{H}, \mathrm{m}, \mathrm{H}-3(\mathrm{C})] ; 6.57[1 \mathrm{H}, \mathrm{d}, J 2.1, \mathrm{H}-6(\mathrm{~A})] ; 6.67[1 \mathrm{H}, \mathrm{d}, J 2.1, \mathrm{H}-8$ (A)]; $7.23[1 \mathrm{H}, \mathrm{s}, \mathrm{H}-2 / \mathrm{H}-6$ ' (B)] confirms the structure of Epigallocatechin.

${ }^{1} \mathrm{H}$ NMR spectra of compound $2\left(300 \mathrm{MHz} ; \mathrm{CDCl}_{3}\right)$ : d 1.25-2.30 (5xOAc, m); $2.87[1 \mathrm{H}, \mathrm{dd}, J 17.7,2.1, \mathrm{H}-4 \beta(\mathrm{C})] ; 2.98[1 \mathrm{H}, \mathrm{dd}, J 17.7,4.2, \mathrm{H}-4 \alpha(\mathrm{C})]$; $5.11[1 \mathrm{H}, \mathrm{s}, J<1, \mathrm{H}-2(\mathrm{C})] ; 5.39[1 \mathrm{H}, \mathrm{m}, J<1, \mathrm{H}-3(\mathrm{C})] ; 6.57[1 \mathrm{H}, \mathrm{d}, J 2.1$, H-6 (A)]; 6.67 [1H, d, J 2.1, H-8 (A)]; 7.20 [1H, d, J 8.4, H-5' (B)]; 7.27 $\left[1 \mathrm{H}, \mathrm{dd}, J 8.4,1.8, \mathrm{H}-6^{\prime}(\mathrm{B})\right] ; 7.36\left[1 \mathrm{H}, \mathrm{d}, J 1.8, \mathrm{H}-2^{\prime}\right.$ (B)] confirms the structure of Epicatechin.

\section{Mass spectrum}

The mass spectra of compound 1 and compound 2 showed a molecular ion peak at $m / z 329(\mathrm{M}+\mathrm{Na})$ and at $m / z 291(\mathrm{M}+\mathrm{H})$ being in agreement with the proposed structure of Epigallocatechin and Epicatechin respectively.

\section{Structure and Molecular Formula of Isolated Chemical Compound}

The molecular formulas of isolated molecules were $\mathrm{C}_{15} \mathrm{H}_{14} \mathrm{O}_{7}$ and $\mathrm{C}_{15} \mathrm{H}_{14} \mathrm{O}_{6}$ which were confirmed by mass spectra and IR data accessible in literature. The IUPAC name of isolated compound 1 and 2 is 2-(3,4,5-trihydroxyphenyl)-3,4-dihydro-2-H-chromene-3,5,7-triol (CAS number: 970-74-1) and 2-(3,4-dihydroxyphenyl)-3,4-dihydro-2Hchromene-3,5,7-triol (CAS Number: 490-46-0) respectively.

\section{DISCUSSION}

Epigallocatechin and epicatechin are flavonoids of the polyphenol group that are most commonly found as a natural product in foods and beverages like grapes, green tea, red wine etc. ${ }^{11}$ Epigallocatechin and epicatechin have been extensively researched for their diverse actions on human health and as therapeutic agents in the treatment of various human diseases. Epigallocatechin and Epicatechin both are the potent polyphenol with various medicinal potentialities like antimicrobial, antioxidant, anti-inflammatory, cardiovascular, neurodegenerative, anti-diabetic, obesity, anti-inflammatory, anti-allergic. ${ }^{12-14}$ Epigallocatechin and Epicatechin also plays crucial role in treatment of human immunodeficiency virus, hepatitis $C$ virus and carcinoma (hepatocellular). ${ }^{15}$ Epicatechin is radio protective, especially used in patients undergoing radiotherapy. ${ }^{15,16}$ Therefore the isolated compounds from root extract of Roscoea purpurea plant possess considerable beneficial therapeutic potential.

\section{CONCLUSION}

Presence of Epigallocatechin and Epicatechin has not been reported in official substitutes (Ashwgandha or Kali Musali) and common adulterants of Roscoea purpurea. It has been reported for the first time from root of Roscoea purpurea (Kakoli) plant. As the market price of Epigallocatechin and Epicatechin is approximately $\$ 80 / \mathrm{g}$ and $\$ 55 / \mathrm{g}$ respectively so, it will be difficult for commercial manufacturers to replace Roscoea purpurea plant with Epigallocatechin and epicatechin just to claim the presence of Roscoea purpurea (Kakoli). Thus, for quality standardization of Roscoea purpurea (Kakoli) containing formulations both these isolated compounds i.e. Epigallocatechin and Epicatechin may be used as chemical markers for differentiation and accurate identification of authentic plants from its substitutes and common adulterants.

\section{ACKNOWLEDGEMENT}

The authors gratefully acknowledge authorities of Baba Farid University of Health Sciences, Faridkot for necessary permission and providing all research facilities.

\section{Source of Support}

This work was supported by the National Medicinal Plants Board (NMPB), Ministry of AYUSH, Govt. of India, New Delhi, India [Grant numbers R\&D/CH-01/2012].

\section{CONFLICT OF INTEREST}

The authors declare no conflict of interest.

\section{ABBREVIATIONS}

TLC: Thin Layer Chromatography; IR: Infrared; NMR: Nuclear Magnetic Resonance; IUPAC: International Union of Pure and Applied Chemistry. 


\section{REFERENCES}

1. Virk JK, Bansal P, Gupta V, Kumar S, Singh R. Lack of pharmacological basis of substitution of an endangered plant group Ashtawarga: A significant ingredient of polyherbal formulations. Am J Phytomed Clin Ther. 2015;2:690-12.

2. Chinmay R, Kumari S, Bishnupriya D, Mohanty RC, Renu D, Padhi MM, et al. Retracted: Pharmacognostical and phytochemical studies of Roscea procera (Kakoli) and Lilium polyphyllum (Ksheerkakoli) in comparison with market samples. Pharmacogn J. 2011;3(25):32-8.

3. Rajashekhar I, Hiren R, Hardik D. A short review on Astavarga plants-losing their existence. IJAPR. 2015;3(7):32-8.

4. Misra A, Srivastava S, Verma S, Rawat AK. Nutritional evaluation, antioxidant studies and quantification of poly phenolics, in Roscoea purpurea tubers. BMC Res Notes. 2015;8(1):324

5. Sahu MS, Mali PY, Waikar SB, Rangari VD. Evaluation of immunomodulatory potential of ethanolic extract of Roscoea procera rhizomes in mice. J Pharm Bioallied Sci. 2010;2(4):346-9.

6. Subramoniam A, Madhavachandran V, Gangaprasad A. Medicinal plants in the treatment of arthritis. Annals Phytomed. 2013;2(1):3-36.

7. Kumar S. Adulteration and substitution in endangered, costly herbal medicinal plants of India, investigates their active phytochemical constituents. Int J
Pharm Ther. 2014;5(4):243-60.

8. Harborne AJ. Phytochemical methods a guide to modern techniques of plant analysis. Springer Science and Business Media. 1998.

9. Kaur VJ, Bansal P, Kumar S, Singh R, Kumar RR. Isolation and Quantification of Chemical Marker of Polygonatum verticillatum: First Report. Cur Traditional Med. 2016;2(3):216-24.

10. Cannell JP. Natural products isolation Human Press. Totawa, New Jersy. 1998.

11. Huang ST, Hung YA, Yang MJ, Chen IZ, Yuann JM, Liang JY. Effects of Epigallocatechin Gallate on the Stability of Epicatechin in a Photolytic Process. Molecules. 2019;24(4):787-92

12. Osuntokun OT, Idowu TO, Gamberini MC. Bio-guided Isolation, Purification and Chemical Characterization of Epigallocatechin; Epicatechin, Stigmasterol, Phytosterol from of Ethyl Acetate Stem Bark Fraction of Spondias mombin (Linn.). Biochem Pharmacol. 2018;7(1):1-9.

13. Epicatechin. Available from: https://pubchem.ncbi.nlm.nih.gov/compound/ Epicatechin 2019.

14. Epigallocatechin. Available from: https://pubchem.ncbi.nlm.nih.gov/compound/ Epigallocatechin 2019

15. Schwarz NA, Blahnik ZJ, Prahadeeswaran S, McKinley-Barnard SK, Holden SL, Waldhelm A. (-)-Epicatechin Supplementation Inhibits Aerobic Adaptations to

Article History: Submission Date : 18-06-2020 ; Revised Date : 16-08-2020; Acceptance Date : 05-10-2020

Cite this article: Kaur G, Gupta V, Singhal RG, Rawal RK, Bansal P. Isolation of Catechins from Roscoea purpurea. J Young Pharm. 2020;12(4):389-91. 